San Jose State University

SJSU ScholarWorks

Master's Theses

Master's Theses and Graduate Research

Spring 2011

\title{
Social Support and Gender Effects on Academic Confidence in Foster Youth
}

Carolyn Suzanne Gillard

San Jose State University

Follow this and additional works at: https://scholarworks.sjsu.edu/etd_theses

\section{Recommended Citation}

Gillard, Carolyn Suzanne, "Social Support and Gender Effects on Academic Confidence in Foster Youth" (2011). Master's Theses. 3929.

DOI: https://doi.org/10.31979/etd.vypx-hx3k

https://scholarworks.sjsu.edu/etd_theses/3929

This Thesis is brought to you for free and open access by the Master's Theses and Graduate Research at SJSU ScholarWorks. It has been accepted for inclusion in Master's Theses by an authorized administrator of SJSU ScholarWorks. For more information, please contact scholarworks@sjsu.edu. 
SOCIAL SUPPORT AND GENDER EFFECTS ON ACADEMIC CONFIDENCE IN FOSTER YOUTH

\author{
A Thesis \\ Presented to \\ The Faculty of the Department of Psychology \\ San Jose State University \\ In Partial Fulfillment \\ of the Requirements for the Degree \\ Master of Arts
}

by

Carolyn S. Gillard

May 2011 
(C) 2011

Carolyn S. Gillard

ALL RIGHTS RESERVED 
The Designated Thesis Committee Approves the Thesis Titled

SOCIAL SUPPORT AND GENDER EFFECTS

ON ACADEMIC CONFIDENCE IN FOSTER YOUTH

by

Carolyn Suzanne Gillard

APPROVED FOR THE DEPARTMENT OF PSYCHOLOGY

SAN JOSE STATE UNIVERSITY

May 2011

Dr. Cheryl Chancellor-Freeland Department of Psychology

Dr. Mildred Alvarez Department of Psychology

Dr. Cary Feria Department of Psychology 


\title{
ABSTRACT \\ SOCIAL SUPPORT AND GENDER EFFECTS \\ ON ACADEMIC CONFIDENCE IN FOSTER YOUTH
}

\author{
by Carolyn S. Gillard
}

Finding the predictors for academic success is critical for foster youth to become productive citizens as adults. The purpose of this study was to investigate the role of social support in the academic confidence of transitional foster youth. Because the literature suggests men and women benefit from social support differentially, I also examined gender as the moderating variable for social support and academic confidence. A sample of 82 foster youth (15-18 years old) from San Joaquin County's Human Service Agency volunteered to participate. Participants were given the Student Perceived Availability of Social Support Questionnaire (SPASSQ) to assess their perceptions of the available social support from foster family, teachers, and peers. The Academic Efficacy Scale (AES) and the School Investment Inventory (SII) were used to assess academic confidence. Hierarchical and linear regression analyses and independent t-tests were conducted to examine the relationship between social support and academic confidence with gender as the moderating variable. Results were that overall social support positively predicted academic confidence, and this was particularly true for females when using AES. More specifically, the social support provided by foster parents was a strong predictor of academic confidence for girls. Teacher and peer support also had a positive impact on foster youths' academic confidence. These data support the hypotheses that social support positively predicts academic confidence and that female foster youth benefit more from social support. 


\section{ACKNOWLEDGEMENTS}

First I would like to take the time to thank God for blessing me with passion to assist foster youth through my personal experiences and my academic endeavors. I would like to thank my long-time mentor and thesis advisor, Dr. Cheryl ChancellorFreeland, for her unconditional support, guidance, and encouragement throughout my undergraduate and graduate studies. She has been very influential and motivating throughout my thesis process, and I am so grateful to have her as my mentor/advisor. When I attempted to stray away from this commitment to complete my thesis due to life's unexpected obstacles and successes, Dr. Cheryl Chancellor-Freeland always managed to keep me focused on the bigger picture, which I can see so much clearer now. I would also like to thank Dr. Mildred Alvarez and Dr. Cary Feria for serving on my thesis committee. Special thanks to my colleagues, Shelina Miranda and Dong Nguyen, who have been my immediate support system from the beginning of my thesis. I also want to thank Barbara Hughes, Tamika Fitch, Gabriel Kallstrom, Kia White, and Michael Suarez for assisting me in numerous ways throughout my graduate studies. Finally, I want to thank my mother Susie Anne Taylor, God-sister Omega Miller, and my best friends Traneil Surrell-Missouri and Chaka Fudge for encouraging and believing in me whenever I would doubt myself. Without the help of all these people, I never would have finished my thesis. Thank you everyone with all my heart, for all your support. 
Table of Contents

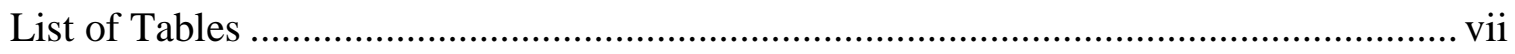

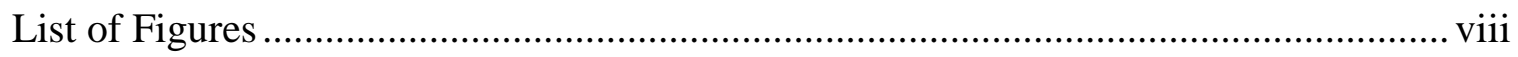

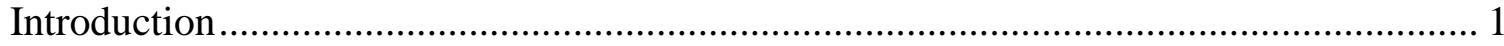

Transitioning Foster Youth .............................................................................. 2

Support, Resiliency, and Academic Challenges of Foster Youth ............................... 5

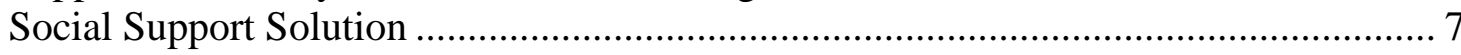

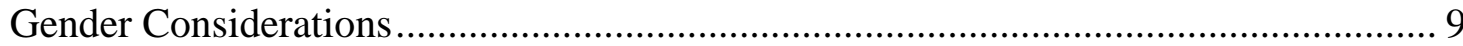

Foster Youth, Social Support, and Academic Success ............................................ 10

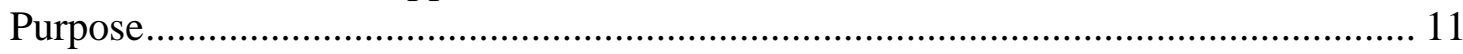

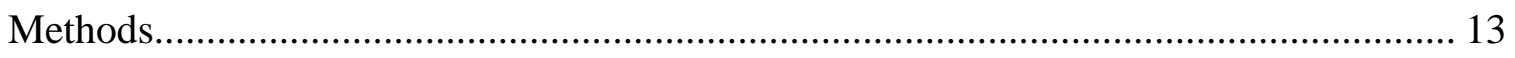

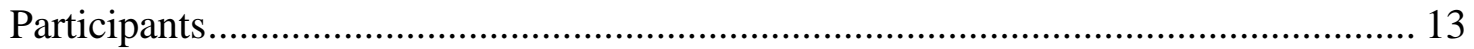

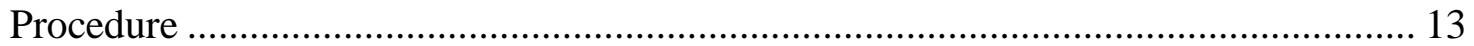

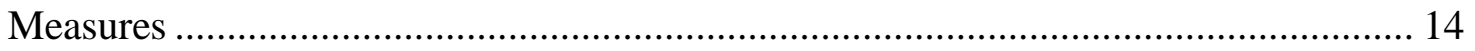

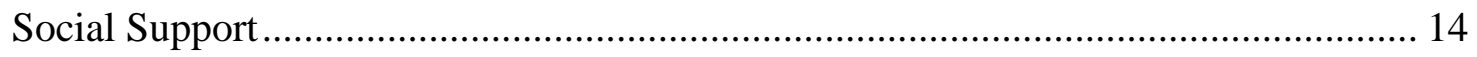

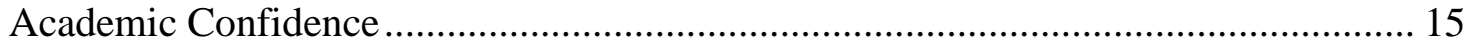

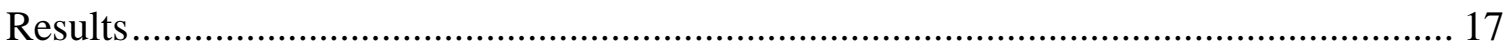

Academic Confidence and Self-Reported Grades ................................................... 17

Social Support and Academic Confidence ................................................................. 20

Sources of Social Support ................................................................................. 21

Social Support Gender Differences and Academic Confidence ................................. 23

Sources of Social Support, Gender, and Academic Confidence............................... 25

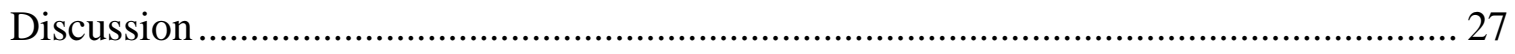

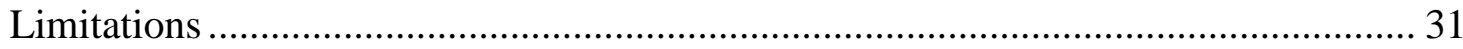

Implications for Further Research ............................................................. 32

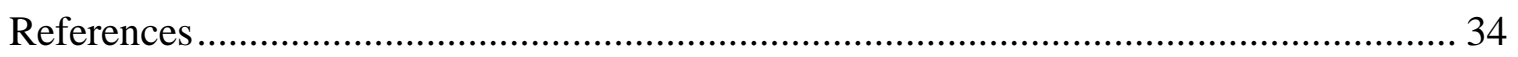

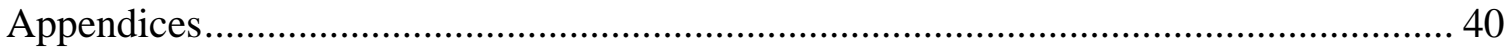

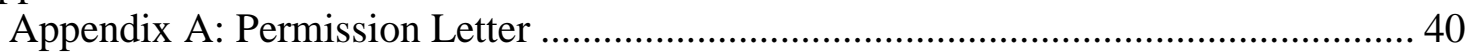

Appendix B: Assent Form for Child Participants .................................................. 41

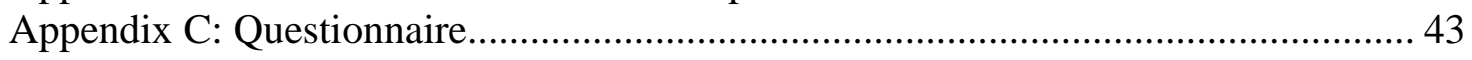




\section{List of Tables}

Table 1. Average Social Support for Overall, Foster Parent, Teacher, and Peer Social

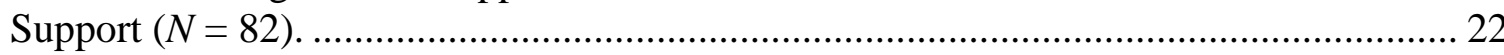

Table 2. Linear Regression Analyses of Overall Social Support, Foster Parent Social Support, Teacher Social Support, and Peer Social Support in Predicting Academic Efficacy $(N=82)$ 


\section{List of Figures}

Figure 1. Scatterplot for the Negative Correlation Between Self-Reported Grades and

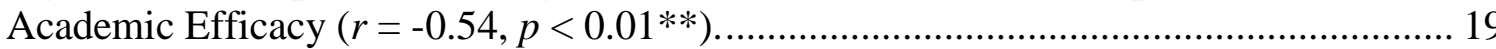

Figure 2. Overall Social Support Significantly Predicts Academic Efficacy for

Females Compared to Male Foster Youth $(p<0.001)$

Figure 3. Foster Parent Social Support Significantly Predicts Academic Efficacy for Females Compared to Male Foster Youth $\left(p<0.01^{*}\right)$. 


\section{Introduction}

In California alone, there are over 100,000 foster children. In the United States, over half a million children are placed in foster care, with 20,000 foster youth maturing out of the foster care system annually (Lemon, Hines, \& Merdinger, 2005; Kelly, 2000). The question for many is, "what next?" In other words, what happens to the foster youth after they exit the system without a safety net? Adolescents who mature out of foster care are expected to automatically, often without preparation, survive independently as adults at 18 years of age. This is substantially younger than the reported average for nonfoster youth (Geenen \& Powers, 2007; Kools, 1997), who often remain with their parents into their early thirties, giving them sufficient time to emerge into adulthood with ease (Arnett, 2000; Furstenberg, Rumbaut, \& Settersten, 2005).

Non-foster youth are typically given the needed time to explore college education and future goals (Gitelson \& McDermott, 2006); however, foster youth often have neither a clear path to higher education nor advanced skill training (Hyde \& Kammerer, 2009). As a consequence, the outcomes for foster youth later in adulthood may be dire, and this topic has been the focus of growing interest among social scientists, clinicians, and the public at large. The purpose of this study was to examine key factors leading to academic success in transitional foster youth. The specific aim was to investigate the role of social support in academic confidence as a predictor for academic success. I also sought to determine whether gender plays a role in this relationship. 


\section{Transitioning Foster Youth}

According to Zetlin, Weinberg, and Kimm (2005), within 12 to18 months after maturing out of foster care, $25 \%$ of males become incarcerated, $60 \%$ of females experience pregnancy, and $38 \%$ of those who become pregnant carry the pregnancy to

term. Research also shows that $45 \%$ of the transitioning foster youth are at risk for being homeless within a year of emancipation, $30 \%$ are substance abusers, and $50 \%$ are likely to have experienced domestic violence (Alan Guttmacher Institute, 1999; McMillian \& Tucker, 1999; Zetlin, Weinberg, \& Kimm, 2003). Furthermore, only 54\% of foster youth graduate from high school, a relatively low figure compared to the $91 \%$ of all non-foster youth who do graduate. It is noteworthy that early academic failure may well predict subsequent negative outcomes such as those described above (Rosenfeld \& Richman, 2003; Zetlin, Weinberg, \& Kimm, 2004).

Such statistics have led to the perception that foster youth are mentally ill or promiscuous or that they are "throwaways" (Zetlin et al., 2003). These negative societal descriptions affect foster adolescents' self-concept and self-esteem as well as their academic confidence and may drive a downward spiral toward a self-fulfilling prophecy (Zetlin et al., 2005). Although a portion of the general population has reportedly blamed foster youth themselves for their own unfortunate outcomes (Zetlin et al., 2004), research suggests that such conclusions are far too simplistic. Issues related to the stability and quality of the placement in a foster family may moderate the support of foster youth and affect their outcomes. Critical evaluation of the literature reveals that environmental factors, such as the stability of placement and the support and guidance given to foster 
youth by their families and other relevant members of the foster care system, greatly impact the academic and overall outcomes of foster youth (Hass \& Graydon, 2009; Rodgers, 2007).

Statistics reveal that $75 \%$ of children placed with foster families have foster parents with unrealistic expectations and who are unable to appropriately tolerate or handle foster adolescents' difficult behaviors. This has resulted in many jeopardized and unstable foster care placements (Mendez, 2008; U.S. Department of Health and Human Services, 2001; Zetlin et al., 2005). Unstable placements are partly due to the failure of foster care agencies to provide the needed emotional, psychological, financial, social, and community support to foster parents after children have been placed (Brown \& Bednar, 2006). The outcomes are not only weak bonding between foster family members, but also often inadequate informal and formal educational training for youth.

The fundamental factors that contribute to poor academic success of foster youth are multiple school transfers and foster home placements and the weak coordinated communication among key people who are either directly or indirectly responsible for the youth's education (e.g., foster parents, foster care agencies, and school personnel) (Vacca, 2006). Lack of communication among those meant to assist foster youth significantly limits their ability to provide youth with the needed emotional support and guidance. This is particularly true for foster youth in need of special education and remedial reading services (Vacca, 2008). Furthermore, the general instability of foster placement causes disruption in the foster parents' ability to effectively represent the educational interests of their foster children (Vacca, 2008). 
Foster children are also reported to be under supported in their general academic pursuits by those close to them. This is in part due to the demands placed on those who work with foster youth (i.e., social workers), who often have large case loads and limited time to devote to each case (Rosenfeld \& Richman, 2003). Moreover, the primary responsibility of many foster care agencies is to protect abused and/or neglected children by placing them in secure environments. The issue of promoting academic success is secondary at best.

It is understandable how social workers can be diverted from addressing the educational needs of foster children (Rosenfeld \& Richman, 2003). However, foster youth may be at risk of failure in school simply because the agencies that serve them do not underscore the importance of education when making placement decisions (Kools, 1999). Foster parents are required to provide a safe environment and to satisfy the basic needs of foster youth, but they are not mandated to monitor and/or to become actively involved in their foster children's academic activities (Kools, 1999; Zetlin et al., 2004). In other words, foster parents are not required to look after foster children's study habits to make sure assignments are completed (Rosenfeld \& Richman, 2003). When foster care providers fail to promote, support, and advocate for foster adolescents' academic endeavors, foster youth lack the social support needed to instill academic confidence, which is a robust predictor for academic success (Kools, 1999). Indeed, the lack of support (emotional and educational) becomes a salient problem when considering its role in academic success and in the success of future endeavors (Kortering \& Brazeil, 2008). 


\section{Support, Resiliency, and Academic Challenges of Foster Youth}

Support in the form of positive reinforcement, such as, praise for positive behavior and consequences when redirection fails, are strong predictors of resiliency in foster youth (Rodgers, 2007). According to Hass and Graydon's (2009) retrospective study, resiliency depends on exposure to problem-solving through modeling and through instruction from authority figures. Researchers have also reported that some foster youth may be more resilient because their easy-going temperaments make it easier to engage adults who are willing to provide social support. However, even when temperaments are defined as "difficult", additional guidance and social support are reported to promote successful problem-solving skills (Hass \& Graydon, 2009).

Successful problem-solving obviously translates well to academic achievement, and this plays a critical role in the economic well-being of youth later in adulthood. In other words, school completion and a strong educational foundation lead to access to productive employment, livable wages, and opportunities for higher education (Kortering

\& Brazeil, 2008). The first learning experience for children is at home, through informal family instruction (Hass \& Graydon, 2009). Children in foster care typically don't have this early training. They are often abused and neglected by their families, and they may be at a particular disadvantage when entering school because they do not benefit from adequate amounts of home education, such as the problem-solving skills mentioned above (Simms, Dubowitz, \& Szilagyi, 2000). Foster children are often behind from the outset, and their early lag in academic achievement may become exacerbated later in life, 
further widening the gap in academic success between them and their non-foster youth counterparts (Zetlin et al., 2004).

Foster youth often experience significant academic problems early relative to nonfoster youth. Researchers have shown $75 \%$ of foster youth perform below grade level and have increased rates of disciplinary referrals and absences. More than 50\% repeat at least one school year and score 15 to 20 percentile points below non-foster youth in statewide achievement tests (Emerson \& Lovitt, 2003; Kools, 1999; Schubert, 2001). Zetlin et al. (2005) discovered that foster youth had overall weaker cognitive abilities, lower academic achievement, and lower standardized reading and mathematics achievement test scores, and more often received special education or an Individual Educational Plan (IEP). That is, while $12 \%$ of the general population receives special education, somewhere between $25 \%$ and $52 \%$ of foster children are placed in special education programs (Kools, 1999). Foster children reportedly need special education for a variety of reasons, such as inadequate prior education, innate or acquired learning disabilities, and emotional disturbances. Instability of placement may have also played a role and this may exacerbate existing scholastic deficiencies. Some investigations have revealed that as many as $50 \%$ of foster children transfer schools at least four times after beginning formal education (Altshuer 1997; Eckenrode, Rowe, Laird, \& Brathewaite, 1995; Emerson \& Lovitt, 2003). Oosterman, Schuengel, Slot, Bullens, and Doreleijers’ (2007) study reported that former foster youth perceived their education to be negatively affected by placement changes. Indeed, this study reported that $90 \%$ who resided in foster care for over 9 years had up to 19 different placements. As stated above, frequent 
residential shifts result in excessive placement of foster youth in special learning programs to accommodate the educational needs identified in IEPs. However, it is uncertain whether these programs actually improve academic performance and reduce dropout rates (Zetlin et al., 2005), and whether such foster youth would benefit more from additional support, such as that from tutoring and counseling (Berrick \& Ayasse, 2005).

\section{Social Support Solution}

As mentioned previously, social support is a strong predictor of resiliency among foster youth. Social support consists of various forms of communication (e.g., admiration, praise, reinforcement, and expressions of encouragement) that require listening, understanding, acceptance, and empathy (emotional support) and may also include instrumental support such as academic resources, feedback, and assistance (instructional support; Vedder, Boekaerts, \& Seegers, 2003). Social support has been identified by several researchers to be a vital and influential component in confidence and academic outcome (Bulstien, Chaves, Gallagher, Grossman, \& Kenny, 2003; Rosenfeld \& Richman, 2003; Vedder et al., 2003). Stable and emotional bonds with adult caregivers affect foster youth's behavioral and emotional profiles, school attendance, and peer social networks (Hyde \& Kammerer, 2009). Successful former foster youth, in other words those who have attended college, reported that people close to them provided forms of social support that were most needed and helpful (Hass \& Graydon, 2009). Resiliency among foster youth seems to depend primarily on the bond between foster youth and their primary caregiver and/or authority figure (Rodgers, 2007). 
Families are widely reported to be the most important source of support for children (Rodgers, 2007; Sarason, Sarason, \& Pierce, 1990; Vedder et al., 2003; Wall, Covell, \& Macintyre, 1999). Because foster youth are separated from their biological families, both physically and emotionally, they often do not receive the support from them. Without adequate support from the foster system, children who live with foster families or in group home settings may not have the emotional and stable support needed to succeed academically (McKeller, 1997). According to Vedder et al. (2003), adolescents believe that adults within their network were responsible for providing a cognitively and linguistically stimulating atmosphere. Social support was reported to be a critical variable in determining their academic achievement (Bulstein et al., 2003). In addition, Wall et al., (1999) found that social support from family had a significant and direct effect on adolescents' experiences at school. Specifically, family support was found to affect patterns of school behavior and to facilitate learning. Several researchers have found that students with significant family social support present greater scholastic self-esteem (Rodgers, 2007; Sarason et al., 1990; Wall et al., 1999). Adolescents also have reported that social support from their parents and teachers was necessary to complete school assignments and to become engaged in academic pursuits (Vedder et al., 2003). In addition, teacher and peer social support have positive effects on adolescents' academics. It is certainly effective to provide a classroom, in which academic rigor and intellectual challenge are accompanied by emotional and instructional support to meet the challenge (Kumar \& Hruda, 2001). Peers are reported to provide support in the classroom when they assist with teacher interactions and school work or assist with 
family issues (Hirsch, Engle-Levy, DuBois, \& Hardesty, 1990). Without these forms of social support, adolescents tend to exhibit increased school difficulties (Wall et al., 1999).

\section{Gender Considerations}

It has been well-documented that females are more likely to seek and receive social support when they perceive they need it (Maccoby \& Jacklin, 1974). This trend for social bonding begins relatively early in adolescent females, resulting in more intimate relationships than observed in adolescent males. When analyzing social interactions, the researchers observed that females have the tendency to be more sensitive to interpersonal relationships and develop more extensive social networks, which has a positive effect on their overall mental and physical health compared to males (Belle, 1982; Maccoby \& Jacklin, 1974). The overwhelming evidence is that females seek and receive more social support, and this is also true where academic endeavors are concerned; however, this is not to say that males do not also benefit from some forms of social support (Vedder et al., 2003).

When considering the effects of gender differences in social support and academic and professional success, researchers have found that females may benefit from multiple sources of social support, such as their families, teachers, and peers. Whereas, males reported that they benefit primarily from social support from their families (Wall et al., 1999). In one study, Wall et al. (1999) sampled 260 male and female students to investigate whether social support affects educational expectations and aspirations. The results were that females who reported higher levels of social support from peers, family, and teachers were more optimistic about future opportunity, and they had higher 
expectations and aspirations for education relative to their male peers. It should also be noted that when Miller and Byrnes (2001) queried 170 non-foster high school students, and they found that older adolescent girls are generally more concerned with academic goals than were older adolescent boys.

\section{Foster Youth, Social Support, and Academic Success}

Academic success may offset some of the negative outcomes of foster youth, as stated previously. Social support is a moderator of confidence, and confidence is expected to be a predictor of academic success, particularly for females (Flouri \& Buchanan, 2002). However, to the best of this investigators knowledge, no study has directly investigated the gender-specific effects of social support on academic confidence for female and male foster youth. Previous research has investigated the role of social support in regards to academic achievement as recalled by former foster youth and nonfoster youth. According to a study by Lemon et al. (2005), 194 former foster youth, who lived in Independent Living Programs (ILP) reported having received more information about financial aid and tutoring, advice about college, and were more likely to decide to attend college than non-ILP former foster youth (i.e., those residing in foster family homes). However, neither ILP nor non-ILP former foster youth felt that the foster care system prepared them well for college. Hass and Graydon's (2009) retrospective study identified 44 former foster youth who reported that faculty and staff members provided a combination of personal support and practical advice, but only $19 \%$ reported that foster families played a positive role in their lives. Research regarding foster youth and academic confidence is relatively sparse, and much of what we know about factors 
leading to academic confidence has come from non-foster youth. Wetterson et al. (2005) revealed that perceptions of social support and academic self-efficacy predicted academic commitment in 689 non-foster adolescents, which help determine their academic confidence. In addition, Bulstein et al. (2003) reported that social support had a positive impact on school performance and work success in 355 non-foster adolescents.

\section{Purpose}

The primary limitations shared by much of the research investigating the relationship between social support and academic confidence in foster youth involve the use of retrospective studies, which is notably prone to error. In other words, investigators have relied on the recalled memories of former foster youth and non-foster youth responses; they have not directly examined the effects of social support on academic confidence among youth currently residing in foster care homes. It is this author's opinion that the well-documented retrieval and recalled errors that are likely associated with retrospective studies (Hass \& Graydon, 2009; Lemon et al., 2005) suggest that direct investigation, rather than a recollection of past events, provide for more accurate data. Therefore, the present investigation directly examined the differential impact of social support on the academic confidence of adolescent males and females currently residing with foster families. Rather than simply looking at self-reported grade point average, academic confidence was assessed because it is reported to be a strong predictor of future academic success (Gore, 2006; Midgley et al., 2000; Peetma, Hascher, Veen, \& Roede, 2005; Sherer et al., 1982). 
I predicted a positive relationship between perceived social support and academic confidence and further predicted that this would be particularly true for female foster youth. The findings are discussed in the context of specific sources of social support. 


\section{Methods}

\section{Participants}

Three hundred surveys were mailed to transitional foster youth between the ages of 15 to 18 years who were currently residing in foster care homes. Cohen's (1988) power analysis suggested that a minimum of 67 participants was needed to detect a significant effect at the 0.05 level. The final participant sample for this experiment included 82 transitional foster youth, 48 females, and 34 males. The mean age of the participants was 16.71 years $(S D=0.81)$. Transitional foster youth taking prescribed psychiatric medication were excluded from the study due to the potential for extraneous negative impacts of the drugs on academics. An incentive consisting of a raffle entry to win a $\$ 25$ Walmart gift card was provided for completion of the survey.

\section{Procedure}

In this study, survey packets were sent to 300 male and female participants from the San Joaquin County foster care transitional youth population (See Appendix A for permission letter from San Joaquin County). Because foster children are wards of the court, informed consent was provided by the county Deputy Director of San Joaquin County Human Services. Assent was also obtained from each transitional foster youth participant. The assent forms explained the purpose of the study and informed the participants that upon completion of the survey that they would be eligible to enter into the \$25 Walmart gift card raffle (See Appendix B). They were told that their participation would be entirely voluntary and that their responses would be confidential. After the consent forms were completed, the remaining survey packet was completed. 
The packet of questionnaires included instruments to assess academic confidence [Academic Efficacy Scale (AES) and the School Investment Inventory (SII)] and social support [Student Perceived Availability of Social Support Questionnaire (SPASSQ)]. A demographic questionnaire was also included (see Appendix C for survey questionnaires).

To maintain the confidentiality of the participants, questionnaires were sent by the deputy director of San Joaquin County Human Services to the foster care homes in which the transitional foster youth currently reside. A stamped return envelope was included with the surveys for the participants to return the entire packet directly back to this investigator.

\section{Measures}

The demographic portion of the questionnaire tracked the adolescents' gender, duration of placement, and prescribed medications. A series of questions regarding academic achievement was also included in the demographic section. The questions inquired if the foster youth had received information about the following; financial aid, college opportunity, tutoring, time on homework, and college preparation classes. The remaining portion of the survey packet included measures of academic confidence and social support (as stated above).

\section{Social Support}

Social support was assessed with the Student Perceived Availability of Social Support Questionnaire (SPASSQ) (Vedder et al., 2003), an 11-item, self-report survey that assesses transitional foster youths' perceptions of available instructional and 
emotional social support from foster families, teachers, and peers. To address foster youth, the social support source "parent" was changed to "foster parent." Respondents rated each item on a 4-point Likert scale from 1 (hardly ever) to 4 (always) based on a continuum. The SPASSQ was estimated to require $10 \mathrm{~min}$ to complete. The scores range from a minimum of 11 points to a maximum of 44 points. The scale has construct validity and an internal consistency that can range from 0.75 to 0.86 .

\section{Academic Confidence}

There is no single instrument with which to assess academic confidence. In this study, the two most often cited instruments were used: the Academic Efficacy Scale (AES) and the School Investment Inventory (SII).

The Academic Efficacy Scale (AES) is a 5-item, 3-min self-report subscale from the Patterns of Adaptive Learning Survey (Midgley et al., 2000). The AES assessed youths' confidence in their ability (or competence) to succeed in their school work. Participants rated items on a 5-point Likert scale from 1 (not at all) to 5 (very true). The scores range from a minimum of 5 points to a maximum of 25 points. The Cronbach alpha is 0.78 , based on non-foster high-school students.

The School Investment Inventory (as modified by; Peetma et al., 2005; Roede, 1989) measured foster youths' intensity and perseverance in school. The School Investment Inventory (SII) has two 14-item subscales called Attending School and Homework in General, which may take 20 minutes to complete. Participants rated items on a 5-point Likert scale from 1 (almost never) to 5 (almost always). The scores can range from a minimum of 28 points to a maximum of 140 points. The internal 
consistency of four European countries varied on the two subscales. The coefficient alpha for Attending School ranged from 0.80 to 0.88 and Homework in General ranged from 0.75 to 0.83 . For the purpose of this study, a few items had to be reworded for clarity. For example, "At school, I keep my attention to school" was changed to "I pay attention when I am in school." All the assessments above were developed for a sixthgrade reading-level competency. 


\section{Results}

It should first be reiterated that of the 300 surveys that were mailed out to transitional foster youth, only 82 foster youth completed and returned the surveys by mail. This $27 \%$ return of the surveys approximated the expected $30 \%$ response rate and provided sufficient power to reveal a medium effect at the 0.05 level (Cohen, 1988).

Participants included 48 females and 34 males with a mean age of $16.71(0.81)$ years. There was no difference in age between males $(M=16.74, S D=0.86)$ and females $(M=16.69, S D=0.78)$. The ethnic composition of participants was $37 \%$ African American, 18\% Caucasian, 33\% Hispanic, and 12\% mixed. Duration of placement ranged from 1 month to over 48 months, with a mode placement duration between 8-19 months.

As previously stated, there is no single established measure for academic confidence; two documented instruments were used to assess this variable. The AES and SII assessments served as indices of academic confidence (Midgley et al., 2000; Peetma et al., 2005; Sherer et al., 1982). Based on 5-point scales, mean and standard deviation scores on these measures were, AES and SII are 3.56 (1.15) and 3.09 (0.41), respectively. It is worth mentioning that these scores are substantially lower than scores reported for non-foster youth, whose mean scores have been reported to range from $3.90-4.90$ across the two measures (Peetma et al., 2005).

\section{Academic Confidence and Self-Reported Grades}

Academic confidence was used in this study because it has been reported to be positively related to future academic performance (Gore, 2006; Midgley et al., 2000; 
Peetma et al., 2005; Sherer et al., 1982); however, grade point average (GPA) has also been used to predict future academic success in previous studies (Long, Monoi, Harper, Knoblauch, \& Murphy, 2007; Zajacova, Lynch, and Espenshade, 2005). As would be expected, some researchers have reported academic confidence to be significantly and positively related to GPA (Zajacova et al., 2005). The associations between self-reported grades and performance on the two academic confidence measures were also examined in this study. Findings were that significant associations were not found for self-reported grades and the SII $(r=-0.19)$ scores. Although, somewhat unexpected, these findings are consistent with other previous reports for non-foster youth (Gore, 2006; Wassenaar, 1994). More unexpectedly, however, a significant negative correlation was found for self-reported grades and AES $(r=-0.54, p<0.01)$, showing that as grades go up, academic efficacy goes down (see Figure 1). This finding is inconsistent with previous reports that have shown non-foster students who had higher academic efficacy also reported higher GPA compared to students with lower academic efficacy (Long, et al., 2007; Zajacova et al., 2005). 


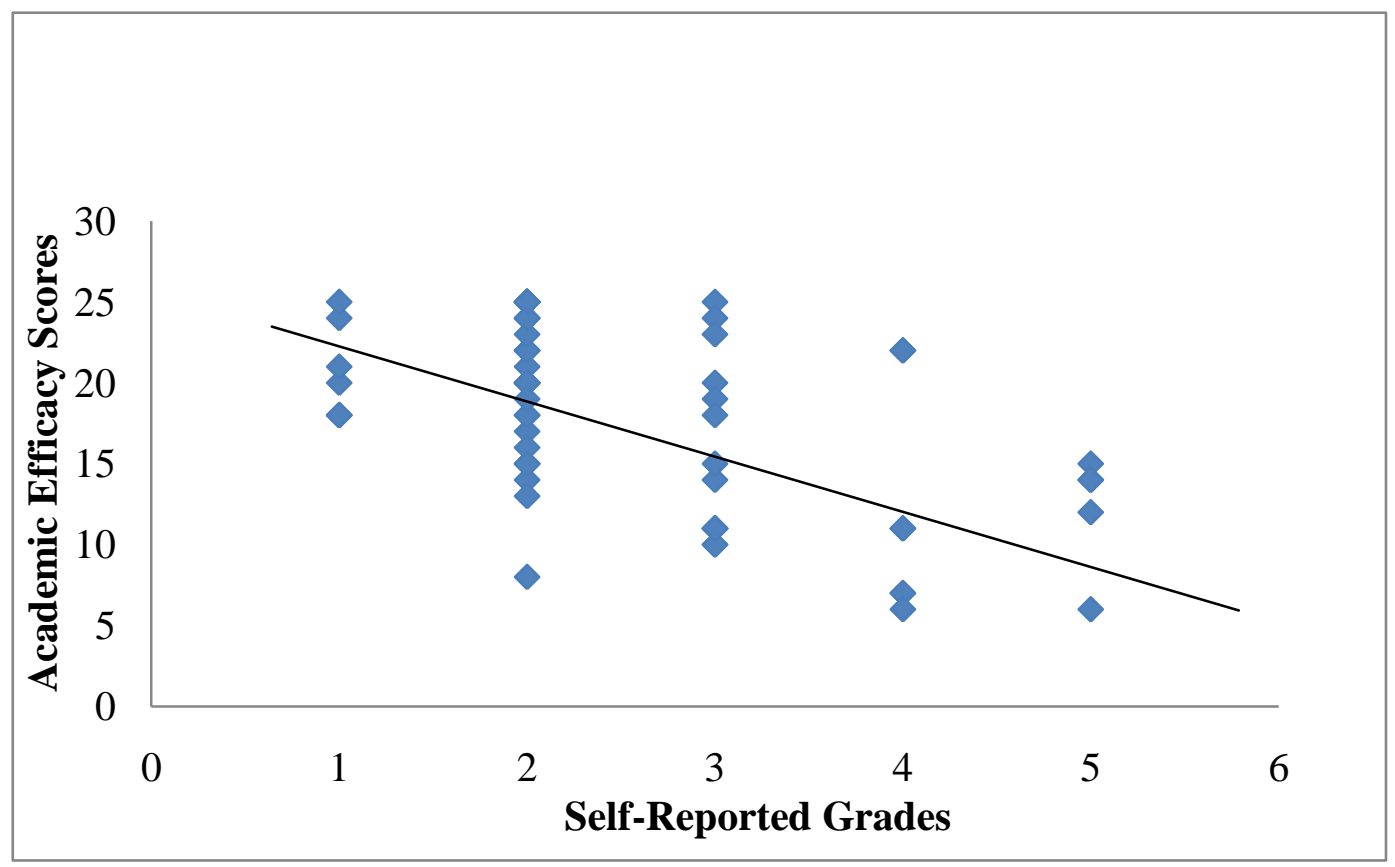

Figure 1. Scatterplot for the negative correlation between self-reported grades and academic efficacy $(r=-0.54, p<0.01 * *)$. 
One possible explanation for this finding is that the grades reported by foster youth were not accurate. Another could be that the foster youth's grades did not reflect a sense of competence. Given that many foster youth participate in alternative education programs in which workload is reduced (e.g., special education programs) (Osgood, Foster, \& Courtney, 2010), I questioned whether and to what degree "effort" (e.g., hours completing homework), would be a better measure of competence and would more likely correspond with academic confidence. Further examination of the data revealed that $44 \%$ of participants $(n=36)$ did not do homework, either because they did not receive homework or because they simply choose not to do their homework. Therefore, associations between academic effort or competence (in this case, hours spent doing homework) and the two academic confidence measures were examined. Results indicated a positive significant relationship for hours spent on homework and AES ( $r=$ $0.20, p<0.05)$. However, no significant associations were found for hours spent on homework and the SII $(r=0.05)$.

\section{Social Support and Academic Confidence}

My primary hypothesis was that perceived social support would predict academic confidence. Linear regression analyses for overall social support and each of the two measures, AES and SII were conducted to test this hypothesis. Results were that no significant relationships were found for overall social support and SII $(\beta=0.16, p=$ 0.16). However, overall social support significantly predicted $\mathrm{AES}, R^{2}=0.18, F(1,80)=$ $17.35, p<0.001,95 \%$ CI $[2.01,5.70]$, which accounts for $18 \%$ of the total variance in $\operatorname{AES}(\beta=0.42)$. 
The findings presented above are that social support predicts academic confidence only when considering the measure of AES. Furthermore, the strongest relationship for academic confidence and academic competence (i.e., hours of homework) was with AES $(r=0.20, p<0.05)$. Therefore, it was assumed that AES represented the best measure of academic confidence, and this is consistent with previous research (Friedel, Cortina, Midgley, \& Turnerand, 2010; Midgley et al., 2000; Peetma et al., 2005). Therefore, the remaining results in this study focused on the relationship of social support with AES.

\section{Sources of Social Support}

Because social support from families has been reported to be a strong predictor of scholastic self-esteem for adolescents (Gore, 2006; Zajacova et al., 2005), the role of specific sources of social support was also examined in this study. Results from independent t-tests indicated that foster youth reported receiving the least amount of social support from their foster parents $(M=2.36, S D=0.92)$, and this was significantly less support than that received from teachers $(M=2.70, S D=0.80), t(81)=-0.310, p=$ 0.003 and from peers $(M=2.68, S D=0.77), t(81)=-0.266, p=0.009$ (see Table 1$)$. 
Table 1. Average social support for overall, foster parent, teacher, and peer social support $(\mathrm{N}=82)$.

\begin{tabular}{lcc}
\hline Predictors & $M$ & $S D$ \\
\hline Overall Social Support & 2.58 & 0.63 \\
Foster Parent Social Support & 2.36 & 0.92 \\
Teacher Social Support & $2.70^{*}$ & 0.80 \\
Peer Social Support & $2.68^{*}$ & 0.77 \\
\hline
\end{tabular}

*Indicates significant differences relative to Foster Parent Social Support $(p<0.05)$.

Additional linear regression analyses were also conducted to assess the relationship between specific sources of social support and AES. Results revealed that in addition to overall social support, support from teachers and peers were also significant predictors of AES ( $p<0.001$ and $p=0.002$, respectively). The relationship between each of the social support dimensions and AES is shown in Table 2, and as can be seen, the strongest associations were for AES and social support from teachers and peers. The relationship for foster parents and AES was not significant $(p=0.052)$. It should be noted that analyses were performed for the other measure of academic confidence (i.e., SII) and social support. Results were that no significant associations were found for overall social support or any of the social support dimensions. 
Table 2. Linear regression analyses of overall social support, foster parent social support, teacher social support, and peer social support in predicting academic efficacy $(N=82)$.

\begin{tabular}{cccccc}
\hline Predictors & $\beta$ & $t$ & $R$ & $R^{2}$ & $95 \%$ CI \\
\hline $\begin{array}{l}\text { Overall Social Support } \\
\quad\end{array}$ & 0.42 & $4.15^{* * *}$ & 0.43 & 0.18 & {$[2.01,5.70]$} \\
$\quad \begin{array}{c}\text { Foster Parent Social } \\
\quad \text { Support }\end{array}$ & 0.23 & 1.97 & 0.23 & 0.05 & {$[-0.01,2.81]$} \\
$\quad \begin{array}{l}\text { Teacher Social Support } \\
\quad\end{array}$ & 0.41 & $3.93 * * *$ & 0.41 & 0.17 & {$[1.45,4.42]$} \\
$\quad$ Peer Social Support & 0.35 & $3.14 * *$ & 0.34 & 0.11 & {$[0.96,4.26]$} \\
\hline
\end{tabular}

Note $. \mathrm{CI}=$ confidence intervals. $* * p<0.01 . * * * p<0.001$.

\section{Social Support Gender Differences and Academic Confidence}

Past research has reported that males and females differentially seek, receive and benefit from social support. A primary prediction in this study was that females would benefit more from social support (Belle, 1982; Maccoby \& Jacklin, 1974). The amount of perceived social support for male and female foster youth was first determined using independent t-tests. Inconsistent with previous findings with non-foster youth, results from this study indicate that male foster youth report receiving significantly more overall social support than female foster youth $(M=2.82, S D=0.59$ and $M=2.41, S D=0.61$, respectively), $t(80)=3.03, p=0.003$. Regarding the specific forms of social support and gender, males reported receiving more support from foster parents $(M=2.64, S D=0.84)$ relative to females $(M=2.15, S D=0.93), \mathrm{t}(80)=2.49, \mathrm{p}=0.015$, and males $(M=2.94$, $S D=0.62)$ also had significantly higher scores than females $(M=2.49, S D=0.81)$ in relation to peer social support, $t(80)=2.78, p=0.007$. The amount of social support 
reportedly provided by teachers did not differ significantly for males $(M=2.86, S D=$ $0.70)$ and females $(M=2.59, S D=0.85), t(80)=1.48, p=0.143$.

A hierarchical regression analysis was computed to investigate the role of gender as a moderating variable for social support and AES. Findings were that there is an interaction for gender and overall social support in relation to $\mathrm{AES}, R^{2}=0.23, \Delta R^{2}=$ $0.05, F(3,78)=7.78, p=0.031,95 \% \mathrm{CI}[0.39,8.18]$, which is $23 \%$ of the total variance $(\beta=0.96)$. Additional linear regression analyses determined that the association of social support and AES is significant only for female foster youth $\left(R^{2}=0.30, F(1,46)=19.11\right.$, $p<0.001,95 \%$ CI $[2.38,14.70])$, which accounts for $30 \%$ of the variance $(\beta=0.54)$, compared to male foster youth $(\beta=0.19, p=0.283$ ) (see Figure 2).

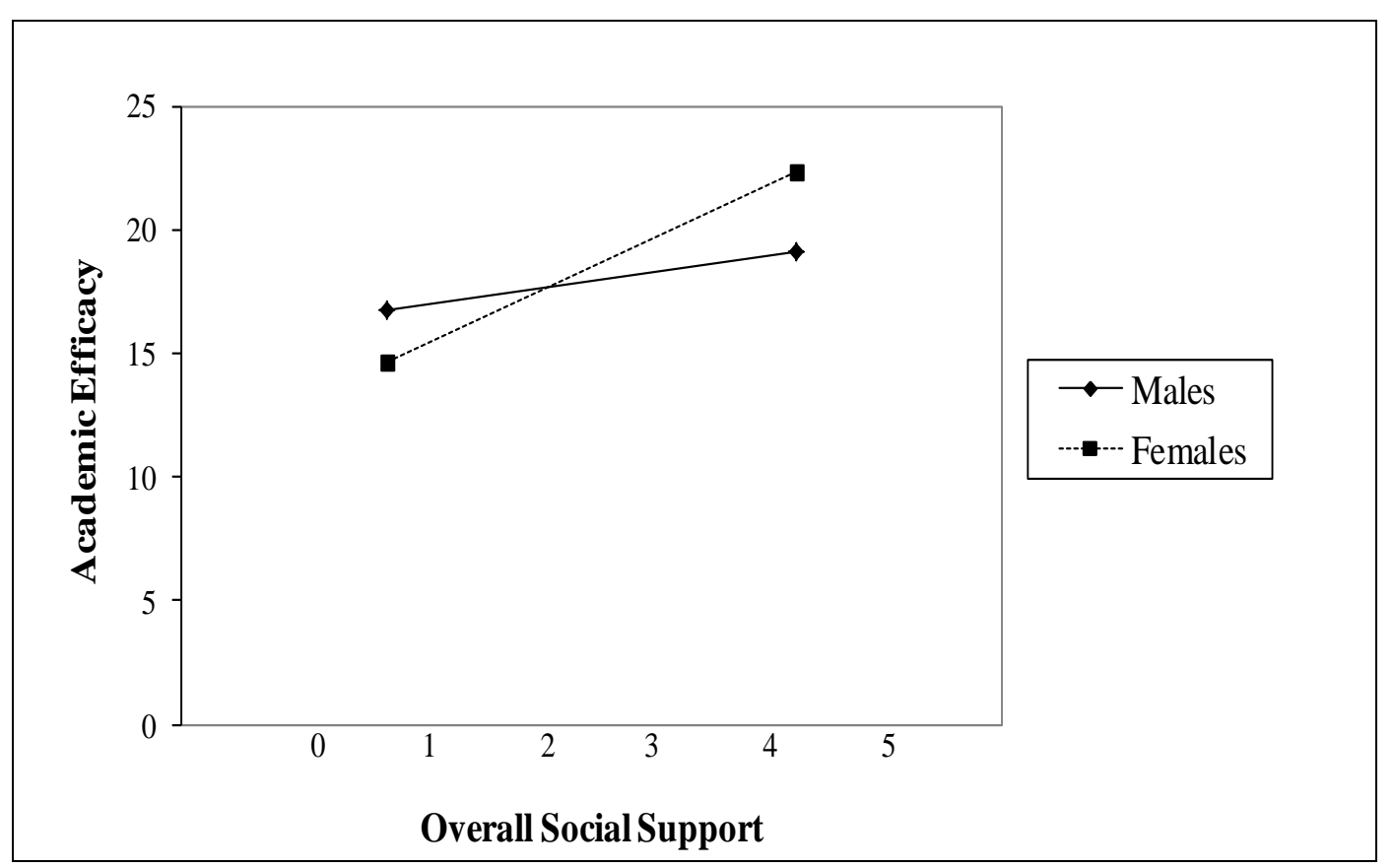

Figure 2. Overall social support significantly predicts academic efficacy for females compared to male foster youth $(p<0.001)$. 


\section{Sources of Social Support, Gender, and Academic Confidence}

Hierarchical regression analyses were utilized to examine the relationship between each social support dimension (foster parent, teacher, and peer) and academic confidence with gender as a moderating variable. Results revealed that foster parent social support has a statistically significant interaction with gender in relation to AES, $R^{2}$ $=0.10, \Delta R^{2}=0.05, F(3,78)=2.90, p=0.043,95 \%$ CI $[0.09,5.84]$. This interaction between gender and foster parent social support accounts for $10 \%$ of the variance in AES $(\beta=0.66)$. In addition, linear regression analyses confirmed that foster parent social support was more beneficial to female foster youth's academic confidence, $R^{2}=0.13$, $F(1,46)=6.69, p=0.013,95 \%$ CI $[0.55,4.41]$, which accounts for $13 \%$ of the variance $(\beta=0.36)$, compared to male foster youth $(\beta=-0.09, p=0.613)$ (see Figure 3). 


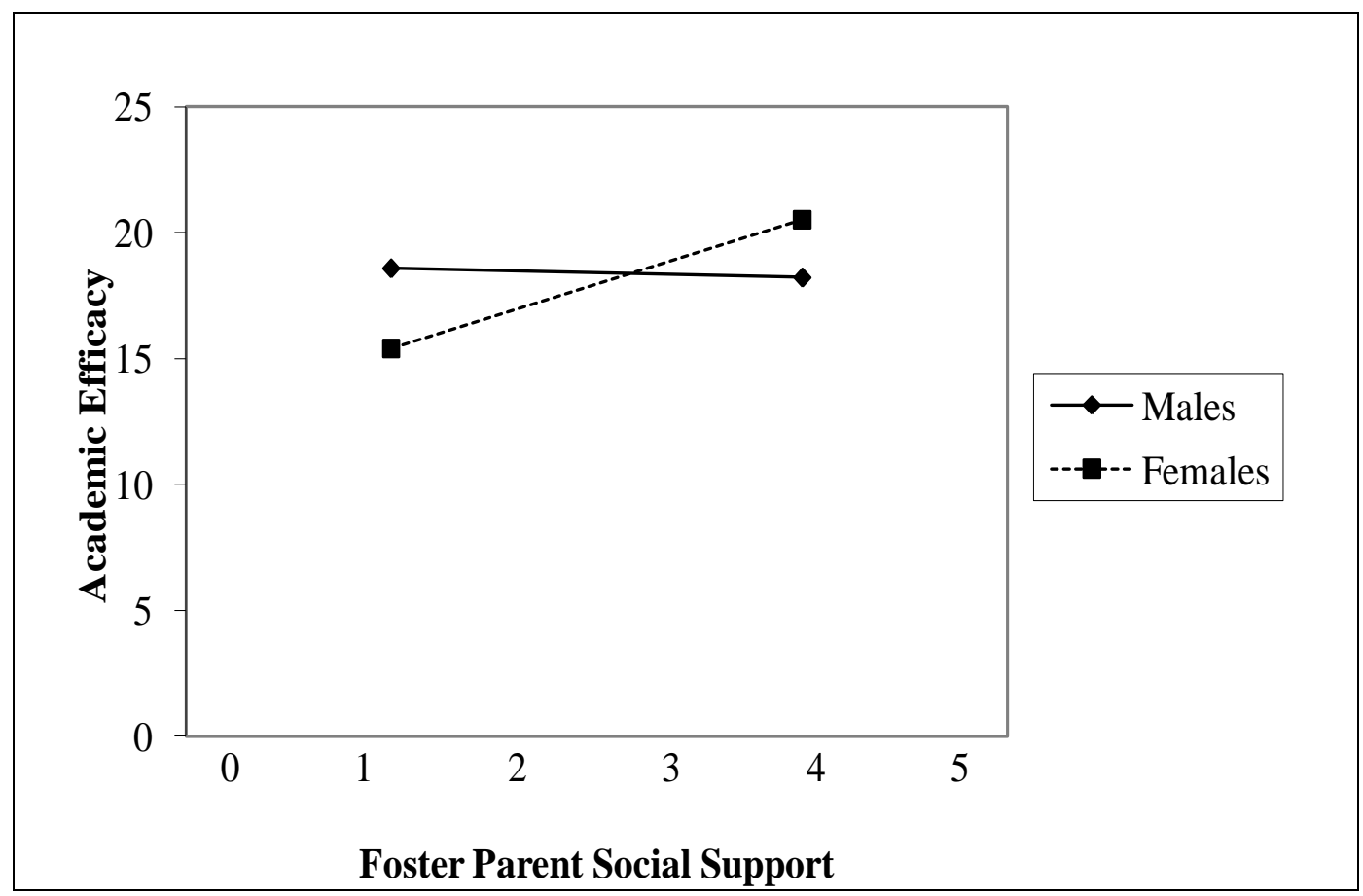

Figure 3. Foster parent social support significantly predicts academic efficacy for females compared to male foster youth $\left(p<0.01^{*}\right)$.

Regarding other sources of social support, hierarchical regression analyses indicate that teacher social support contributes $17 \%$ of the total variance in AES $(\beta=$ 0.41), indicating that social support from teachers significantly predicts academic confidence, $R^{2}=0.17, F(2,79)=7.96, p=0.001,95 \%$ CI $[-2.44,2.35]$. A main effect for peer social support and AES was also found $(\beta=0.35)$, which accounts for $12 \%$ of the total variance, $R^{2}=0.12, F(2,79)=5.13, p=0.008,95 \%$ CI $[-2.17,2.93]$. However, a significant interaction effect with gender was not observed. Gender does not significantly interact with either teacher support, $(\beta=0.58, p=0.149)$ or peer support, $(\beta$ $=-0.18, p=0.682$ ) when predicting AES. 


\section{Discussion}

Social support has been identified as an essential and prominent component in confidence and academic outcomes in non-foster youth (Bulstien et al., 2003; Rosenfeld \& Richman, 2003; Vedder et al., 2003). In addition, social support has been recognized as a strong predictor of resiliency among former foster youth in relation to their academics (Rodgers, 2007). The purpose of this study was to investigate the impact of social support on academic confidence in male and female youth currently residing in foster homes.

For the most part, research has shown that social support positively predicts academic confidence in non-foster and former foster youth (Bulstien et al., 2003; Hass \& Graydon, 2009; Kortering \& Brazeil, 2008; Rodgers, 2007; Vedder et al., 2003). However, previous studies have not directly examined the relationship of social support on academic confidence for youth currently residing in foster homes. The present study was conducted to determine whether social support has a positive relationship with the academic confidence of foster youth. Furthermore, because females are reported to seek, receive, and benefit from social support relative to males (Maccoby \& Jacklin, 1974; Wall et al., 1999), this investigator predicted that social support would be a particularly strong predictor of academic confidence for female foster youth, compared to male foster youth.

Academic success involves much more than just grades and standardized test scores, and this is particularly true for non-traditional students such as the foster youth. It is this author's belief that research should include other important dimensions of 
academic outcomes, such as academic confidence, which has been reported to predict future academic success. As there is no one indicator of academic confidence, this study initially examined the two most prominent measures of academic confidence (i.e., AES and SII) as predictors of future academic success. However, results ultimately focused on one measure, AES. AES has been previously reported to be a particularly strong indicator of academic confidence in non-foster student populations, and in this study, it was the only measure that had a significant association with academic effort, another likely indicator of sense of competence. AES was also the only measure of academic confidence that was associated with social support.

Although SII has been used to assess academic confidence for non-foster student populations, it may have been less accurate when assessing the academic confidence of foster youth. The SII measures school habits, which includes survey items such as, "I have no trouble with going to school." Responses to questions such as these may not be accurate or appropriate when querying foster youth students, particularly when considering that multiple and transient placements would clearly impact school engagement and study habits (Gore, 2006; Rosenfeld \& Richman, 2003).

The AES, in contrast, was designed to assess youth's confidence in their ability to succeed in their school work. Questions in this survey included items such as, "Even if the work is hard, I can learn it," and items such as these reportedly measure perseverance in the face of academic challenge. Responses to such questions may have been less affected by unstable foster home placements. 
As stated above, overall social support was found to be a positive predictor of academic confidence as determined by the AES responses, and this is consistent with this study's primary hypothesis. The second hypothesis was also supported, and that was that social support would greatly impact academic confidence for female foster youth, a prediction based on previous research (Maccoby \& Jacklin, 1974; Wall et al., 1999). It is interesting to note, however, that even though overall social support did not predict academic confidence for male foster youth, males reported receiving significantly more overall social support than females, and this is not consistent with findings with nonfoster youth males (Vedder et al., 2003). This finding may have been due to the fact that male foster youth seek overall social support for a variety of different reasons that do not include academic confidence or achievement such as, esteem, belonging, and attachment. Social support may also have a positive effect on male foster youth well-being and can decrease the intensity of stress during difficult times and life altering transitions such as those commonly experienced by male foster youth (Mendez, 2008).

Unrelated to the hypotheses of this study, specific sources of social support were also examined. Family social support and parental expectations have been purported to be particularly strong influences of academic achievement. Given past reports that the bond between foster youth and their primary caregiver and/or authority figure determine resiliency (Rodgers, 2007), this variable was also examined. Social support dimensions were broken down to examine the effects of social support from foster parents, teachers, and peers on foster youth academic confidence (i.e., AES). Findings were that teacher and peer social support were positive predictors of AES in foster youth, and there was no 
significant difference between males and females. However, foster parent social support predicted academic confidence only for female foster youth. These findings support previous research with non-foster youth which suggested that females benefit from social support from multiple sources in relation to their academics (Maccoby \& Jacklin, 1974; Wall et al., 1999). It also suggests that regardless of the type of family, parental guidance and involvement are vital for a female's ability to academically succeed (Sarason et al., 1990).

Present findings, however, are inconsistent with previous reports that male nonfoster youth benefit from specifically family social support (Vedder et al., 2003). In this study, male foster youth did not benefit from foster parent social support in relation to their academic confidence. One possible explanation concerns the type of social support provided to foster youth. Some foster parents are not well equipped to provide informational support regarding academics (Kumar \& Hruda, 2001), and foster parents may differ in their level of expertise to help their foster youth make informed decisions about their academic future (Kumar \& Hruda, 2001). This form of instrumental social support is most often sought by males, and may have been critical in predicting AES in male foster youth.

Lastly, the unexpected finding for a negative correlation between self-reported grades and AES merits some discussion. Based on previous research, it was expected that competence in school work would be reflected in academic grades and that academic confidence would therefore be strongly associated with self-reported grades. Interestingly, there were no associations between self-reported grades and SII. Moreover, 
the relationship between self-reported grades and AES was significantly and inversely related, that is, the higher the grades, the less confident, (i.e., the lower the AES score), a finding that is inconsistent with previous research (Long et al., 2007; Zajacova et al., 2005). Although there are multiple possible explanations for this result I questioned the assumption that self-reported grades reflected a sense of competence, a question that has been previously raised by others (Gore, 2006; Wassenaar, 1994). This question becomes even more salient when considering the foster youth population. Foster youth are typically over-represented in alternative education (continuation school) and special education programs (Kools, 1999; Velasco et al., 2008), and these programs are reported to involve a less rigorous curriculum with lower academic standards (Kumar \& Hruda, 2001; McLaughlin, Atukpawn, \& Williamson, 2008). Therefore, foster youth may have been getting good grades with little effort, explaining the lack of correlation between selfreported grades and academic confidence. Whether or not the participants in the present study were involved in these types of academic programs was not tracked and remains unknown. However, I was able to examine whether the effort put into academic achievements or amount of time spent on homework corresponded with academic confidence. It is interesting to note that the AES positively correlated with hours spent on homework. In other words, foster youth who took the initiative to do their homework showed an increase in academic confidence.

\section{Limitations}

This study contains limitations related to sample size, geographic location, and the questionnaires that were used. Even though the sample size $(N=82)$ was determined 
to be sufficient to reveal a medium effect (Cohen, 1988), it consisted largely of underrepresented ethnic minorities and may not have been representative of the foster care population in other parts of the country. The questionnaires that were utilized in this study reported reliability and validity measures that were sufficient, as determined by non-foster populations. However, as was discussed in the context of the SII, this measure might not have been appropriate for foster youth. Also, the demographic questions did not inquire about the type of school (traditional, alternative, or home school) that the foster youth are currently attending, which could have been an explanation for the significant negative correlation between self-reported grades and academic confidence. Finally, this study did not carefully track number and duration of placements. Given that stability of foster placement plays a major role in the education quality and consistency as well as the degree of support received by foster families, this study was unable to determine the degree to which foster home placements played a role in this study's findings.

\section{Implications for Further Research}

This study was valuable in demonstrating the importance of social support on academic confidence in transitional foster youth and in demonstrating that female foster youth, just like females in general, benefit more than males from social support in relation to their academics. This study is the first of its kind to specifically receive responses from transitional foster youth who are currently residing in foster care regarding their social support and academic confidence. This research provided a unique contribution to the existing literature on the relationship between social support and 
academic confidence among foster youth, and it may have provided some insight into the measure that would be most appropriate in determining academic confidence in foster youth. In the future, a research design that includes foster youth's grades from school records, examining if academic confidence translates to academic performance, the identification of the type of school youth are attending (traditional school vs. alternative school), and the measurement of the type of social support would greatly enhance the overall findings. Lastly, this research on the relationship between foster youth's social support and academic confidence may lead to changes within foster care agencies, such that academic achievement would be underscored when defining foster parents roles and duties. 


\section{References}

Alan Guttmacher Institute, AGI, (1999). Teenage pregnancy: Overall trends and state-by-state information. New York, NY: Author.

Altshuler, S. J. (1997). A reveille for school social workers: Children in foster care need our help. Social work in Education, 19 (2), 121-128. Retrieved May 9, 2007, from http://weblinks3.epnet.com/ citation.asp

Arnett, J. (2000). Emerging adulthood: A theory of development from the late teens through the twenties. American Psychologist, 55(5), 469-480.

Belle, D. (1982). Lives in stress; women and depression. Beverly Hills, CA: Sage Corporation.

Berrick, J. D., \& Ayasse, R. H. (2005). Improving educational services for foster youth living in group homes: An analysis of interagency collaboration. California Social Work Education Center. Berkeley: University of California at Berkeley, Retrieved August 13, 2010, from http://www.csulb.edu

Brown, J. D., \& Bednar, L. M. (2006). Foster parent perceptions of placement breakdown. Children and Youth Services Review, 28 (12), 1497-1511. Retrieved June 16, 2009, from doi: 10.1016/j.childyouth.2006.03.004

Bulstein, D. L., Kenny, M. E., Chaves, A., Grossman, J. M., \& Gallagher, L. A., (2003). The role of perceived barriers and relational support in the educational and vocational lives of urban high school students. Journal of Counseling Psychology, 50 (2), 142-155. Retrieved December 12, 2007, from doi: 10.1037/0022-0167.50.2.142

Cohen, J. (1988). Statistical power analyses for the behavioral sciences. Hillsdale, NJ: Lawrence Erlbaum.

Eckenrode, J., Rowe, E., Laird, M., \& Brathewaite, J. (1995). Mobility as a mediator of the effects of child mistreatment on academic performance. Child Development, $66,1130-1142$.

Emerson, J., \& Lovitt, T. (2003). The educational plight of foster children in schools and what can be done about it. Remedial \& Special Education, 24 (4), 199-203. Retrieved December 12, 2007, from http:0infotrac.galegroup.com 
Flouri, E., \& Buchanan, A. (2002). The role of work related skills and career role models in adolescents career maturity. The Career Development Quarterly, 51 (1), 36-43.

Friedel, J. M., Cortina, K. S., Turner, J.C., \& Midgley, C. (2010). Changes in efficacy beliefs in mathematics across the transition to middle school: Examining the effects of perceived teacher and parent goal emphases Journal of Educational Psychology 102 (1), 102-114. Retrieved June 5, 2010, from doi: $10.1037 / \mathrm{a} 0017590$

Furstenberg F. F., Rumbaut, R. G., \& Settersten, R. A. (2005). On the frontier of adulthood emerging themes and new directions. Illinois, $\mathrm{CH}$ : University of Chicago Press.

Geenen, S., \& Powers, L. E. (2007). Tomorrow is another problem: the experience of youth in foster care during their transition to adulthood. Children and Youth Services Review, 29(8), 1085-1101.

Gitelson, I. B., \& McDermott, D. (2006). Parents and their young adult children: Transitions to adulthood. Child Welfare Journal, 85(5), 853-866.

Gore, P. A. (2006). Academic self-efficacy as a predictor of college outcomes: Two incremental validity studies. Journal of Career Assessment, 14(1), 92-115. Retrieved August 13, 2010, from doi: 10.1177/1069072705281367

Hass, M., \& Graydon, K. (2009). Sources of resiliency among successful foster youth. Children and Youth Services Review, 31, 457-463. Retrieved November 16, 2008, from doi:10.1016/j.childyouth.2008.10.001

Hirsch, B. J., Engle-Levy, A., DuBois, D. L., \& Hardesty, P. H. (1990). Traditional views of social support and their impact on assessment. In B. R. Sarason, I. G. Sarason, \& G. R. Pierce (Eds.), Social Support: An Interactional View. New York: John Wiley. 367-394.

Hyde, J., \& Kammerer, N. (2009). Adolescents' perspective on placement moves and congregate settings: complex and cumulative instabilities in out-of-home care. Children and Youth Services Review, 31, 265-273. Retrieved August 16, 2008, from doi:10.1016/j.childyouth.2008.07.019

Kelly, K. (2000). The education crisis for children in the California Juvenile Court System. Hastings Constitutional Law Quarterly, 27, 757-774. Retrieved February 16, 2007, from http:web.lexis.com/universe/document 
Kools, S. M. (1997). Adolescent identity development in foster care. Family Relations, 46(3), 263-271.

Kools, S. M. (1999). Self protection in adolescents in foster care. Journal of Child and Adolescent Psychiatric Nursing, 12(4), 139-147.

Kortering, L., \& Braziel, P. (2008). Engaging youth in school and learning: The emerging key to success and completion. Psychology in Schools, 45(5), 461-465.

Kumar, R. \& Hruda, L. Z. (2001). "What do I want to be when I grow up?" Role of parent and teacher support in enhancing students' academic confidence and educational expectations. American Educational Research Association: University of Michigan. Retrieved August 18, 2010, from http://www.umich.edu

Long, J. F., Monoi, S., Harper, B., Knoblauch, D., \& Murphy, P. K. (2007). Academic motivation and achievement among urban adolescents. Urban Education, 45(3), 196-222. Retrieved September 7, 2010, from doi: 10.1177/0042085907300447

Lemon, K., Hines, A. M., \& Merdinger, J. (2005). From foster care to young adulthood. The role of independent living programs in supporting successful transitions. Children and Youth Services Review, 27, 251-270. Retrieved December 12, 2007, from doi:10.1016/j.childyouth.2004.09.005

Maccoby, E. E., \& Jacklin, C. N. (1974). The psychology of sex differences. Stanford, California: Stanford University Press. 393-627.

McKeller, N. (1997). Foster homes. In Bear, G. G., Minke, K. M. \& Thomas, A. (Eds.), Children's needs II: Development, problems and alternatives. Bethesda, MD: National Association of School Psychologists. 697-706.

McLaughlin, M., Atukpawu, G., \& Williamson, D. (2008). Alternative education options in California: A view from counties and districts. Stanford University.

McMillian, C. J., \& Tucker, J. (1999). The status of older adolescents at exit from out of home care. Child Welfare, 78, 339-362.

Mendez, S. L. (2008). Support networks and the effects they have on foster youth's academic success. Thesis: California State University, Long Beach, CA.

Midgley, C., Maehr, M. L., Hurda, L. Z., Anderman, E., Anderman, L., Freeman, K. E., ...Urdan, T. (2000). The multi-dimensional manual for the patterns of adaptive learning survey. Ann Arbor, Michigan: University of Michigan. Retrieved March 8, 2007, from http://www.umich.edu pals 
Miller D. C. \& Byrnes, J. P. (2001). To achieve or not to achieve: a self-regulation perspective on adolescents' academic decision making. Journal of Educational Psychology, 93(4), 677-685. Retrieved March 6, 2008, from doi:10.1037//0022

Oosterman, M., Schuengel, C., Slot, N. W., Bullens, R. A. R., \& Doreleijers, T. A. H. (2007). Disruptions in foster care: a review and meta-analysis. Children and Youth Services Review, 20(1), 53-76.

Osgood, D. W., Foster, E. M., \& Courtney, M. E. (2010). Vulnerable populations and the transition to adulthood. The Future of Children 20(1). Retrieved October 22, 2010, from http://www.princeton.edu/futureofchildren/publications/journals

Peetsma, T., Hascher, T., Veen, I., \& Roede, E. (2005). Relations between adolescents self- evaluations, time perspectives, motivation for school, and their achievement in different countries at different ages. European Journal of Psychology of Education, 20(3), 209-225.

Rosenfeld, L. B., \& Richman, J. M. (2003). Social support and educational confidence for students in out of home care. Children and Schools, 25(2), 69-86.

Roede, E. (1989). Explaining student investment: An investigation of high school of students' retrospective accounts of their investment in school. Dissertation. University Amsterdam. Retrieved March 8, 2007, from http:/www.scokohnstamminstituut.uva.nl

Rodgers, Y. H. (2007). Adolescents adjusting to a group environment: A residential care model of re-organizing attachment behavior and building resiliency. Children and Youth Services, 29, 1131-1141.

Sarason, I. G., Sarason, B. R., \& Pierce, G. R. (1990). Social support: The search for theory. Journal of Social and Clinical Psychology, 9(1), 133-147.

Sherer, M., Maddux, J. E., Mercandante, B., Prentice-Dunn, S., Jacobs B., \& Rogers, R. W. (1982). Psychological Reports, 51, 663-671.

Shubert, R. (2001). Hard numbers may aid students in foster care. Seattle PostIntelligence Reporter 1. Seattle Post - Intelligencer, B2.

Simms, M., Dubowitz, H., \& Szilagyi, M. (2000). Health care needs of children in the foster care system. Pediatrics, 106(4), 909. 
U.S. Department of Health and Human Services, Administration for Children and Families, Administration on Children, Youth, and Families, Children's Bureau (2001). Adoption and foster care analysis and reporting system. Washington, DC: Author.

Vacca, J. S. (2006). Foster children need to learn how to read. Relational Child and Youth Care Practice, 19(4).

Vacca, J. S. (2008). Breaking the cycle of academic failure for foster children: what can schools do to help? Children and Youth Services Review, 30, 1081-1087.

Retrieved December 12, 2007 from doi:10.1016/j.childyouth.02.003

Vedder, P., Boekaerts, M., \& Seegers, G., (2003). Perceived social support and wellbeing in school; role of student's ethnicity. Journal of Youth and Adolescents, 34(3). 269-278. Retrieved March 6, 2008, from doi:10.1007/S10964-005-4313-4

Velasco, J. R., Austin, G., Dixon, D., Johnson, J., McLaughlin, M., \& Perez, L. (2008). Alternative education options: A descriptive study of California continuation high schools. John W. Gardner Center for Youth and Their Community. 1-12 Retrieved March 6, 2008, from http://openarchive.stanford.edu/bitstream/10408

Wall, J., Covell, K., \& Macintyre, P. D. (1999). Implications of social support for adolescents' education and career aspirations. Canadian Journal of Behavioral Science, 31 (2), 63-71.

Wassenaar, C. M. V. (1994). The relationship between academic motivation and academic achievement of selected first time students at Grand View college. Thesis: Drake University, Des Moines, IA.

Wetterson, K. B., Guilimino, A., Herrick, C. G., Hunter, P. J., Kim, G.Y., Jagow, D., ...McCormick, J. (2005). Predicting educational and vocational attitudes among rural high school students. Journal of Counseling Psychology, 52(4), 658-663. Retrieved May 9, 2008, from doi:10.1037/0022-0167.52.4.658

Zajacova, A., Lynch, S. M., Espenshade, J. L. (2005). Self-efficacy, stress, and academic success in college. Research in Higher Education, 46(6), 677-706. Retrieved August 13, 2010, from doi: 10.1007/s11162-004-4139

Zetlin A.G., Weinberg L., \& Kimm, C. (2003). Are the educational needs of children in foster care being addressed? Children and Schools, 25, 105-119. 
Zetlin A.G., Weinberg L., \& Kimm, C. (2004). Improving education outcomes for children in foster care: Intervention by an education liaison. Journal of Education for Students at Risk, 9(4), 421-429.

Zetlin A.G., Weinberg L., \& Kimm, C. (2005). Helping social workers adder the educational needs of foster children. Child Abuse \& Neglect, 29, 811-823. Retrieved December 12, 2007, from doi:10.1016/j.chiabu.2004.12.2009 


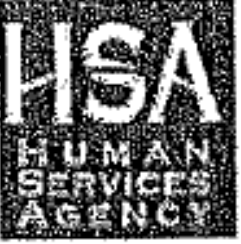

Appendices

Appendix A: Permission Letter

\section{SAN JOAQUIN COUNTY}

May 14, 2008

P.O. Box 201056

102 South San Joaquin Street

Stockton, CA 95201-3006

Tel (209) 468-1000

CalWORKS

Children's Services

Aging and Community Services

San Jose State University

Mary Graham Children's Shelter

Master of Art Program-

Experimental Psychology

To Whom It May Concern,

The San Joaquin County Human Service Agency has given Carolyn Gillard, a graduate student in the Masters of Arts Program- Experimental Psychology, permission to submit and receive back a questionnaire from foster children. We are supportive of Ms. Gillard's thesis research on the topic of the impact of social support and type of foster care placement in academic outcomes in transitional foster youth.

We requested that Ms. Gillard provide us with a cover letter to foster youth, a questionnaire, and a self addressed and stamped return envelope inside each stamped mailing envelope. We will then place mailing labels on each envelope and place each packet in the mail. This will protect the confidentiality of each foster child. A court order is not required for this process to occur, as no confidential information is being provided to Ms. Gillard.

It is essential that the confidentiality of the foster youth not be compromised.

If you have any questions, please contact me.

Very Truly Yours,

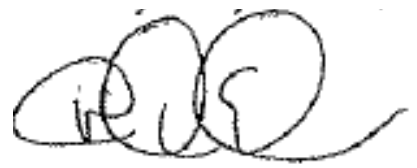

David Erb

Deputy Director- Children's Services

DE: jlc

(209)468-1190

derb@co.san-joaquin.ca.us

Our Hission is to fead in the 
Appendix B: Assent Form for Child Participants

Responsible Investigator: Carolyn Gillard

Title of Protocol: Social Support and Academic Confidence

1. You have been asked to participate in a research study investigating social support in relation to your academic confidence.

2. You will be asked to provide general demographic and background information about yourself, and to complete a survey that measures your perceived social support, sense of personal and academic mastery, and school investment.

3. Although the results of this study may be published, no information that could identify you or your family will be included.

4. Minimal risk due to questions about your prescribed medication and social support you receive from your foster parent(s), but the risks will not cause discomfort or affect you.

5. For your participation in this study by completing the survey, you will be entered into a \$25 Walmart gift certificate raffle. Your participation can assist with developing transitional foster youth programs that will promote higher education (vocational schools and college) for future foster youth.

6. Questions about this research may be addressed to Carolyn Gillard (209) 992-1684 or Dr. Cheryl Chancellor-Freeland (408) 924-5645. Complaints about the research may be presented to Dr. Sheila Bienenfeld, Chair of Psychology, at (408) 924-5600. Questions about a research subjects' rights, or research-related injury may be presented to Pamela Stacks, Ph.D., Associate Vice President, Graduate Studies and Research, at (408) 924-2480.

7. No service of any kind, to which you are otherwise entitled, will be lost or jeopardized if you choose to "not participate" in the study.

8. Your consent to participate is being given voluntarily. You may refuse participation in the entire study or in any part of the study. You have the right to not answer questions you do not wish to answer. If you participate in the study, you are free to withdraw at any time without any negative effect on your relations with San Jose State University or with any other participating institutions or agencies. You also have the right to withdraw from the study at any time.

Initial 
Your agreement to participate is indicated by you completing and returning the attached survey. Please keep this letter for your records.

Thank You

Carolyn Gillard

Investigator's Signature

Date 


\section{Appendix C: Questionnaire}

Fill in the blanks and the answer that applies to you.

Demographics

Age:

Ethnicity:

Gender: Male Female

Duration of placement: $\quad$ Short term (1 -8 months)

Moderate term (19-48 months)

Long Term (over 48 months)

What prescribed medications are you taking?

Which of the following best describes your grades so far in high school?

$$
\begin{aligned}
& 90-100=\mathrm{A} \ldots \ldots . .1 \\
& 80-89=\mathrm{B} \ldots \ldots . .2 \\
& 70-79=\mathrm{C} \ldots \ldots .3 \\
& 60-69=\mathrm{D} \ldots \ldots .4 \\
& \text { Below } 60 \ldots \ldots . .5
\end{aligned}
$$

Approximately what is the number of hours you spend on homework a week?

No homework is ever assigned......... 1

I have homework but do not do it...... 2

Less than 5 hours a week................ 3

Between 5 and 10 hours a week....... 4

More than 10 hours a week........... 5

Do you have a tutor? (circle one) Yes No

Are you attending college preparation classes? (circle one) Yes No

Whatever your plans, do you believe you have the ability to complete college?

Yes, definitely 1

Yes, probably 2

Not Sure 3

I doubt it 4

Definitely Not 5

Has anyone told you about financial aid? (circle one) Yes No Have you ever received advice about college? (circle one) Yes No 
Circle an answer for each social support person (hardly ever $=1$ lowest, always $=4$ highest).

\section{Social Support}

Student Perceived Availability of Social Support Questionnaire (SPASSQ)

When you don't understand a lesson, who can you count on to explain it to you?

\begin{tabular}{|c|c|c|c|}
\hline Foster Parent & o hardly eves & o sometimes never & $\circ$ often \\
\hline cher & $\circ$ hardly eves & o sometimes never & $\circ$ often \\
\hline Peer & o hardly eves & o sometimes never & $\circ$ often \\
\hline
\end{tabular}

If you received a failing grade, when you thought your work was satisfactory, whom could you ask for an explanation of your grade?

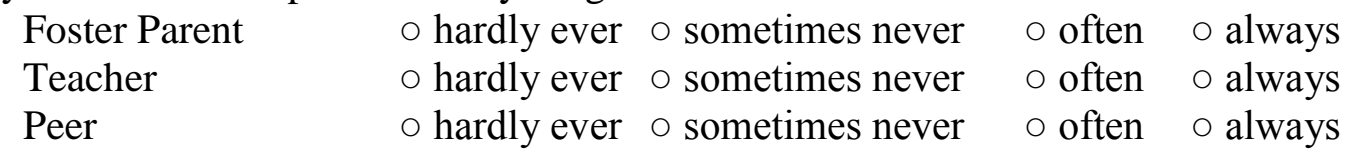

Who encourages you when your performance is weaker than usual?

\begin{tabular}{|c|c|c|c|}
\hline ster Parent & o hardly ever & o sometimes never & O often \\
\hline & o hardly ever & o sometimes never & $\circ$ often \\
\hline Peer & o hardly ever & o sometimes never & O often \\
\hline
\end{tabular}

When you need advice, whom can you turn to?

\begin{tabular}{|c|c|c|c|}
\hline Foster Parent & $\circ$ hardly ever & o sometimes never & O often \\
\hline Teacher & $\circ$ hardly ever & o sometimes never & $\circ$ often \\
\hline Peer & $\circ$ hardly ever & o sometimes never & O often \\
\hline
\end{tabular}

When you are not able to complete your schoolwork, whom can you ask for help?

\begin{tabular}{|c|c|c|c|}
\hline Foster Parent & o hardly ever & o sometimes never & $\circ$ often \\
\hline Teac & $\circ$ hardly ever & o sometimes never & $\circ$ often \\
\hline Peer & $\circ$ hardly ever & o sometimes never & o often \\
\hline
\end{tabular}

Whom can you go to with your personal problems?
Foster Parent
$\circ$ hardly ever $\circ$ sometimes never
$\circ$ often $\bigcirc$ always
Teacher
$\circ$ hardly ever $\circ$ sometimes never
$\circ$ often $\circ$ always
Peer
$\circ$ hardly ever $\circ$ sometimes never
$\circ$ often
$\circ$ always

Who shows that he or she is happy when you perform well?

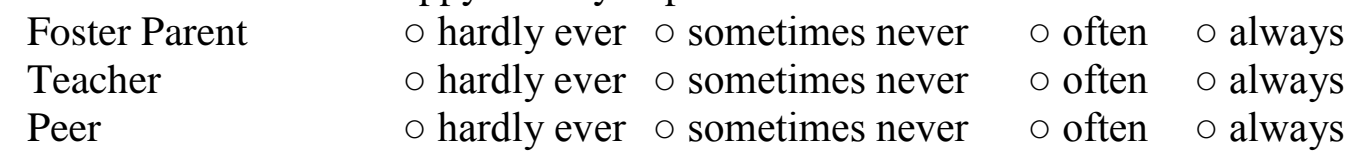


Who is prepared to help you when you have problems with your homework?

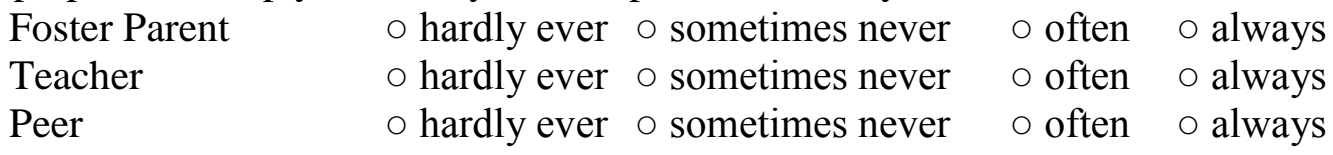

When you just can't get something right, who can you count on to show how it's done? Foster Parent $\circ$ hardly ever $\circ$ sometimes never $\circ$ often $\circ$ always

Teacher $\quad \circ$ hardly ever $\circ$ sometimes never $\circ$ often $\circ$ always

Peer $\circ$ hardly ever $\circ$ sometimes never $\circ$ often $\circ$ always

Who shares your feelings when you are happy?

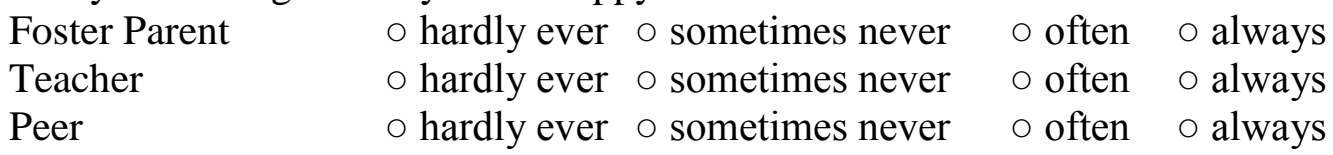

Who shares your feelings when you are sad?

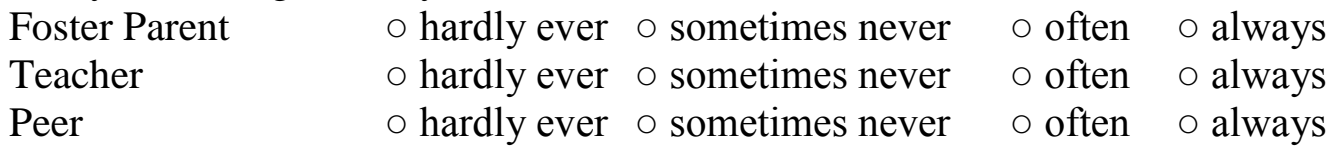

Circle an answer for each item (1 the lowest, 5 the highest)

\section{Academic Confidence}

Academic Efficacy Scale (AES)

Not at all True Somewhat True Very True

I am certain I can master the skills taught in class this year.................. 1

I am certain I can figure out how to do the most difficult class work........... ${ }_{1}{ }_{2}$

I can do almost all the work in class if I don't give up...................... ${ }_{1}{ }_{2}$

Even if the work is hard, I can learn it.................................... $1_{2}$

I can do even the hardest work in my class if I try...... 